\title{
Achalasia of the Cardia in Sibs
}

\author{
N. DAYALAN, LAXMI CHETTUR, and M. S. RAMAKRISHNAN \\ Department of Paediatric Surgery, Institute of Child Health and Hospital for Children, Egmore, Madras, India
}

Dayalan, N., Chettur, L., and Ramakrishnan, M. S. (1972). Archives of Disease in Childhood, 47, 115. Achalasia of the cardia in sibs. A family is reported in which 3 children were affected by achalasia cardia proved by investigations, and possibly 4 more children had this condition. An autosomal recessive mode of inheritance is suggested.

Achalasia of the cardia is uncommon in children, and has rarely been reported in sibs. We report a family with 3 children having proved achalasia and 4 more children who died with symptoms similar to the other 3 children.

\section{Case Reports}

Case 1. The first child, a girl aged $1 \frac{1}{2}$ years, the sixth child of the family, was brought on 7 April 1966 with a history of vomiting and regurgitation of feeds of 6 months' duration. The child was marasmic and dehydrated. Other investigations showed a moderate anaemia. Plain $x$-ray of the chest revealed a widened mediastinum due to a distended oesophagus, and barium swallow demonstrated a picture of a typical achalasia cardia (Fig. 1). After a few days of preparation with intravenous fluids and blood transfusions a transabdominal modified Heller's operation was performed on 26 April 1966. Since the operation (Fig. 2), she has been symptom free and growing normally.

Case 2. The second patient, the seventh child of the same family, a boy aged 1 year, was brought to us in February 1969 with repeated respiratory infections and regurgitation of feeds. He was also marasmic and investigations showed a primary complex (Fig. 3). Barium swallow showed a hold-up of barium in the terminal oesophagus and absent gas bubble in the fundus of the stomach (Fig. 4). This child was treated for the primary complex and surgery was advised. The parents had the operation postponed, and the child was admitted later with fulminating tubercular meningitis and gross inanition and died.

Case 3. The third patient, the 8th child of the same family, a boy aged 11 months, was brought to us in January 1971 with a history of vomiting and upper respiratory infections. He was ill nourished and a barium swallow showed an achalasia of the cardia. After a few days of preparation, a transabdominal

Received 12 August 1971 modified Heller's operation was done and the child is doing well (Fig. 5).

Motility studies were not done on these 3 cases in view of their very young age. The barium swallow studies were conclusive in all the cases. All 3 cases showed on fluoroscopy irregular and abnormal peristalsis, occasional skipping of peristaltic waves, and inhibition of normal cardio-oesophageal relaxation to the

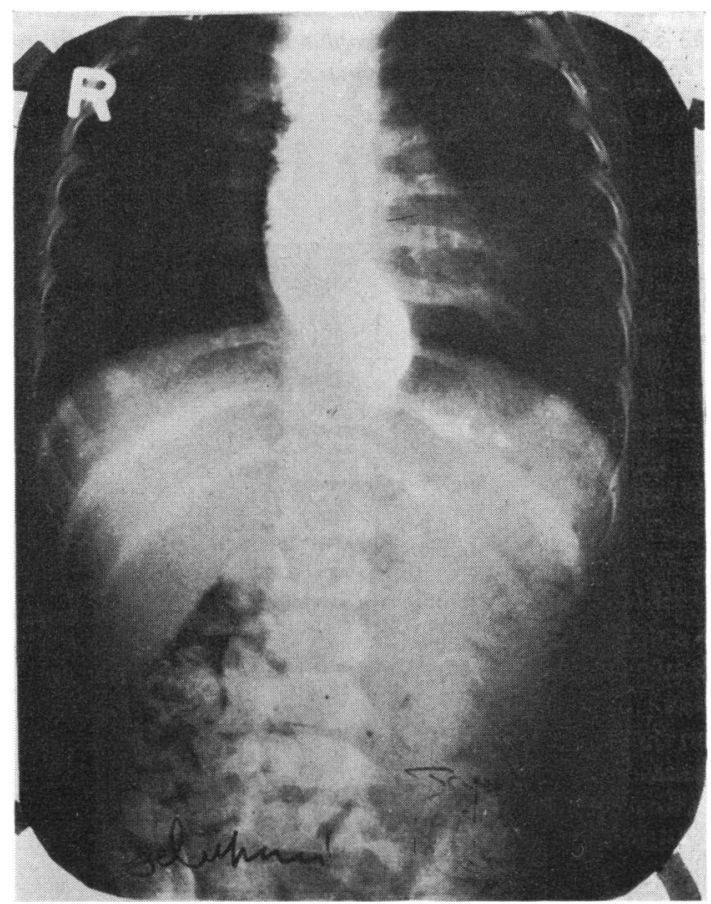

FIG. 1.-Preoperative barium swallow of Case 1 showing the narrow cardio-oesophageal junction and dilated oesophagus. There is a mixture of barium and air along the right border of oesophagus. The fundus gas shadow is absent. 


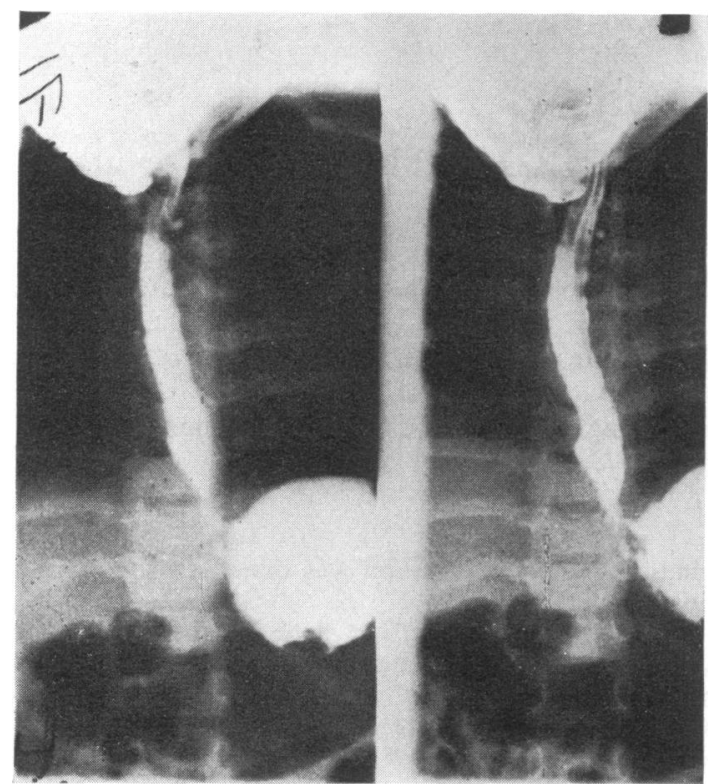

FIG. 2.-Postoperative barium swallow of Case 1 showing the diminishcd size of the oesophagus and the ready filling of stomach.

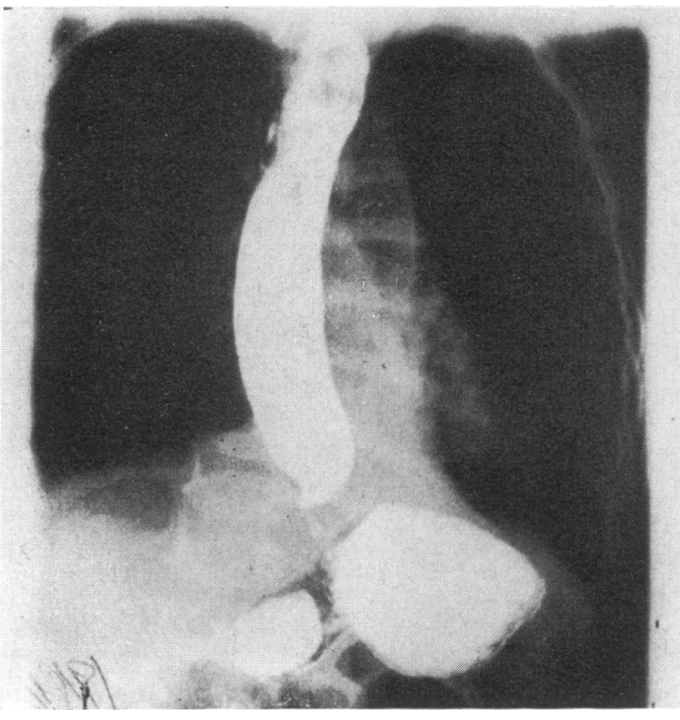

FIG. 4.-Barium swallow of Case 2, showing the dilated and mildly curved oesophagus-narrow cardio-oesophageal junction.

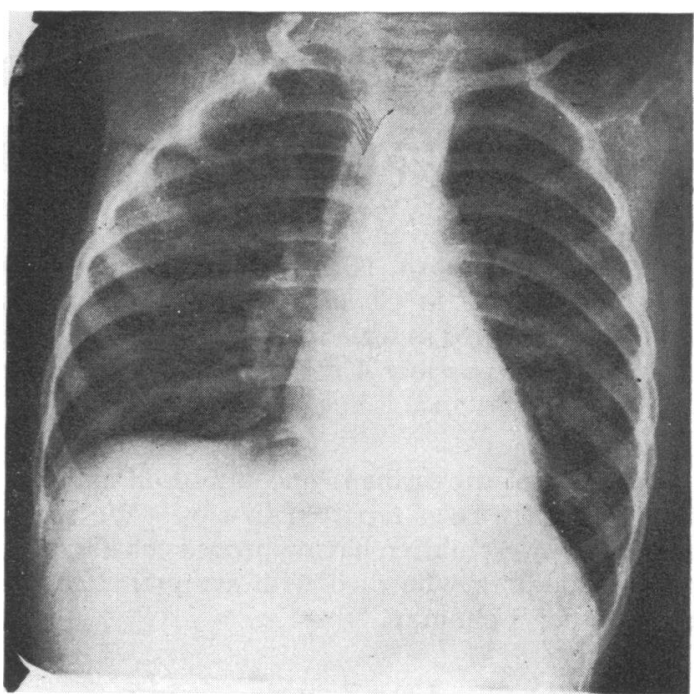

FIG. 3.-Plain x-ray of chest of Case 2 showing dilated oesophagus. No fluid level is seen in this film. Retrocardiac shadow left side present.

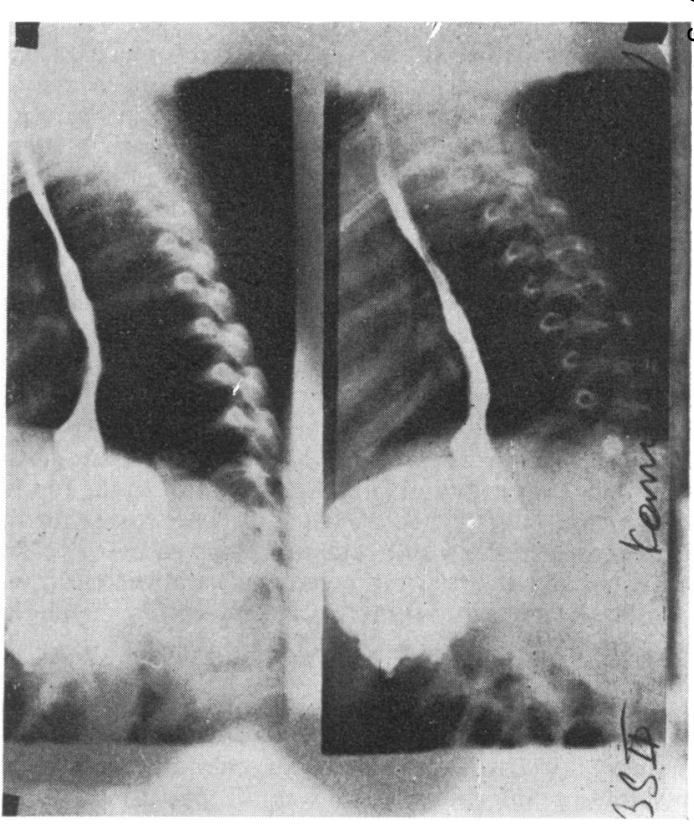

FIG. 5.-Postoperative film of Case 3 showing the normal sized oesophagus and normal functioning cardio-oesophageal junction. 
passage of the barium bolus. These findings on fluoroscopy correspond with the observation of absence of the normal stripping wave and with abnormal movements during motility studies, and hence are characteristic of achalasia.

All 4 children-the first, second, fourth, and fifth child of the family-who are dead, had, according to the parents, an exactly similar history of vomiting and repeated respiratory infections, starting in the first year of life. Though achalasia of the cardia is the most probable cause of death in these children, we have no positive proof since these children were not seen by a doctor at any time. Of the 8 children in the family only 1 , the third child, is alive and not affected.

We studied the family tree for five generations (Fig. 6). We also did barium swallow studies on the mother, father, and the unaffected child in the family, and they were found to be normal. The father of these children was operated on for duodenal ulcer as was the grandmother who is also their mother's elder sister.

Chromosome analysis, sex chromatin analysis, and dermatoglyphs were done for the patients, their parents, and the unaffected sib, and all were normal.

\section{Discussion}

Achalasia of the cardia is infrequently reported in infants and children. Children account for about $5 \%$ of the total reported cases of achalasia cardia (Cameron, 1927). The existence of this condition in neonates and infants is even doubted by some authors (Roviralta Astoul, 1967) who believe that the disorder is too often confused with such conditions as chalasia, hiatus hernia, and congenital strictures. Olsen, Holman, and Andersen (1953) in their review of 601 cases could find only 8 who were less than 10 years old and another 24 in whom the symptoms of dysphagia developed before the age of 10 years. Payne, Ellis, and Olsen (1961) from the Mayo Clinic could find only 27 cases with this condition in a period of 14 years. Though this condition is indeed difficult to recognize in the newborn, it is often possible to trace the symptoms in proved cases in older infants and children back to early infancy. Of the 27 cases reported by Payne et al. (1961), 10 manifested symptoms within the first year. Langmead (1920) had reported this condition in a 15-month-old infant.

Our own experience consists of only 5 cases, including the 3 reported cases here, out of a total of 30,000 new patients seen in the last 5 years. Though achalasia may occasionally be a disorder of neonates, it rarely occurs in members of the same family. Instances of its occurrence in twins and brothers have been reported. Di Bello and Zilli (1960), Nagler et al. (1963), and Ellis and Olsen from the Mayo Clinic (1969) have reported this

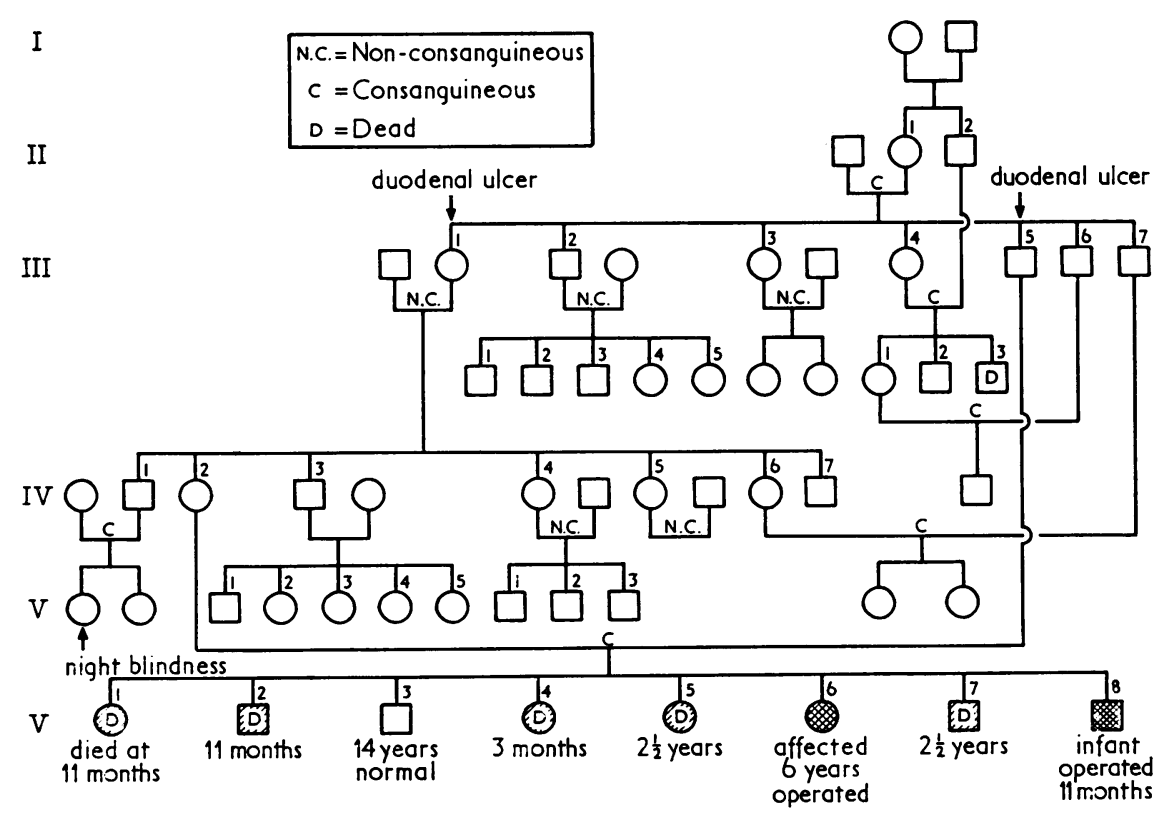

FIG. 6.-The family tree for 5 generations is charted. Only 1 generation is affected. Consanguineous marriage is practised quite frequently. We have also investigated the children of III.7 and IV.6. (Brother of the present patients' mother.) All the children are normal. 
condition in brothers. Thibert et al. (1965) have reported a familial form of achalasia in an infant and also in brothers in 2 related families. Almost all these patients except that of Thibert et al. (1965) were adults. Our report is of special interest in that all the cases were children and all of them developed symptoms within the first year of life.

The parents of the propositi are closely consanguineous, the father being the maternal uncle of the mother. The paternal grandparents are also consanguineous.

In the family both males and females are affected in the same generation and hence the inheritance is autosomal and not sex-linked. Though 7 out of the 8 children are affected, dominance is ruled out since both parents are unaffected. There are no other affected subjects except in the group under study. The family tree for which details are available for 5 generations show that consanguineous marriages are practised to a great extent. It is very likely that the gene pool has become concentrated. Hence, the possibility is that both the parents are heterozygous carriers of an autosomal recessive gene for the trait.

Of course, with a heterozygous recessive trait, 7 out of 8 children being affected is rather unusual but not impossible. However, the high frequency of occurrence makes one wonder if there is any selective force operating in favour of the affected gene. At this stage of knowledge there is no conclusive proof for such a factor though linkage studies could prove useful. It appears that if a genetic factor is responsible for the disease condition, it is an autosomal recessive trait.
The possibility of any environmental factors being the cause of the disease was also investigated, but no such factor was seen to be common to all pregnancies. No drugs were administered during pregnancies. There is no history of any viral infection to the mother during any of the pregnancies nor of irradiation of any kind.

Our thanks are due to the director and superintendent, Institute of Child Health and Hospital for Children, Madras, for permission to publish these cases.

\section{REFERENCES}

di Bello, B., and Zilli, L. (1960). Associazione di cancro e megasofago in duo fratelli. Acta Chirurgica Italica, 16, 267.

Cameron, J. A. M. (1927). Oesophagectasia in a child. Archives of Disease in Childhood, 2, 358.

Ellis, F. H., Jr., and Olsen, A. M. (1969). Achalasia of the Esophagus (Major Problems in Clinical Surgery, Vol. IX), p. 66. Saunders, Philadelphia and London.

Langmead, F. (1920). Notes of a case of oesophagectasis in an infant with radiograms. Proceedings of the Royal Society of Medicine, (Sect. Dis. Child.), 43.

Nagler, R. W., Schwartz, R. D., Stahl, W. M., Jr., and Spiro, H. M. (1963). Achalasia in fraternal twins. Annals of Internal Medicine, 59, 906.

Olsen, A. M., Holman, C. B., and Andersen, H. A. (1953). The diagnosis of cardiospasm. Diseases of the Chest, 23, 477.

Payne, W. S., Ellis, F. H., Jr., and Olsen, A. M. (1961). Treatment of cardiospasm (achalasia of the esophagus) in children. Surgery, 50, 731.

Roviralta Astoul, E. (1967). Hernies Hiatales et Ectopies Partielles de l'Estomac chez l'Enfant. Masson, Paris.

Thibert, F., Chicoine, R., Chartier-Ratelle, G., Thibodeau, L. P., Collin, P. P., and Collu, R. (1965). Forme familiale de l'achalasie de l'oesophage chez l'enfant. Union Médicale du Canada, 84, 1293.

Correspondence to Dr. M. S. Ramakrishnan, Institute of Child Health and Hospital for Children, Egmore, Madras-8, India. 